\title{
Using Concrete and Abstract Models to Help a Special Needs Third Grader Master Whole Number Addition
}

\author{
Estella P. De Los Santos, Barba Aldis Patton \\ University of Houston-Victoria
}

\begin{abstract}
A case study was used to investigate a third-grade student's knowledge of whole number addition. The overall goal of the work was to improve the student's understanding of addition concepts including one and two digit addends with and without regrouping. The information gained from the pre-test was used to develop an individualized education plan for the student. Anodal records were kept on the student's advancement and to monitor the progress. A posttest was given at the conclusion.
\end{abstract}

\section{Introduction}

This investigation was conducted during the summer following the student completing the third grade school year. The student has been in inclusion classrooms and has gone to special education classrooms for reading, writing, and mathematics since pre-kindergarten. The student was diagnosed with mild retardation prior to beginning the first grade and was performing at least one level below grade level in the three subjects during the third grade.

According to the student's third-grade reports, the student was having difficulty with several mathematics concepts including addition. The student had been introduced to several models in mathematics such as counters, touch points, base-ten blocks, a hundred chart, multi-link blocks and the number line. The teacher observed that the student seemed to lose focus when presented with various models. In this study, the researchers decided to only use the base ten blocks as a concrete manipulative. The researchers addressed addition concepts with one and two digit addends with and without regrouping.

The research objectives of the study were: 1) to assess the student's knowledge of addition concepts, 2) to develop an individualized education plan (IEP) and 3) to use the IEP to improve the student's comprehension of whole number addition with one and two digit addends with and without regrouping.

\section{Literature Review}

The National Council of Teachers of Mathematics has set as one of the standards for grades Pre-K through $2^{\text {nd }}$ grade: "develop and use strategies for whole-number computations, with a focus on addition and subtraction" [1]. The Common Core State Standards Initiative [2] states that second grade students should "use place value understanding and properties of operation to add and subtract". Knowledge of what addition means and how to add numbers is necessary before students can progress to problems requiring higher level thinking such as application type word problems. Many students with learning disabilities fail to achieve an understanding of basic math facts such as addition [3].

Young children come into their first classroom eager to learn and enthusiastic about formally learning math [4]. They have been counting cars and classifying cars into colors for several years and most likely even before being able to make complete sentence $[5,6,7]$. Those two activities seem to be favorites with parents as they drive and try to keep little ones entertained as they travel daily. This informal mathematics instruction is very important. These are positive experiences with mathematics and will influence the child's formal instruction greatly [5]. A major component of the elementary mathematics curriculum focuses on the student's ability to successfully complete word problems. However, this seem to bring the situation into a circular motion as the child must be able to do basic computation in order to be successful with the word problems but must be able to do word problems to be successful in the elementary mathematics curriculum [7]. Research illustrates the importance that the child has a very solid foundation and be able to do basic addition and subtraction $[8,9]$.

When the child enters school, the positive enthusiasm often makes a 180 degree turn and the child may even develop a task-avoidant behavior and or mathematics anxiety. Children who have special needs often can't maintain focus on a list of task the same as their peers who do not have special needs [4, $10,11]$. Mathematics is no longer fun to the children with any learning problems as it becomes too complex due to the list of tasks required to complete 
work $[12,13]$. Now, the child is focusing on the algorithms so much that he/she is not able to internalize the concept $[14,15,16,17,18]$.

Researchers in this study and other studies [19, 20] have followed a concrete-representationalabstract (CRA) model used by Mercer and Miller [3] to help young children learn basic math facts such as addition, subtraction, multiplication, and division concepts. See Figure 1 below. The model is also referred to as a concrete-semi concrete-abstract (CSA) model [21]. In the first stage concrete objects are used such as base ten block manipulatives, in stage two semi-concrete objects are used such as pictures or drawings of the base ten blocks, and in the third stage abstractions are used such as writing addition problems in vertical form on paper.

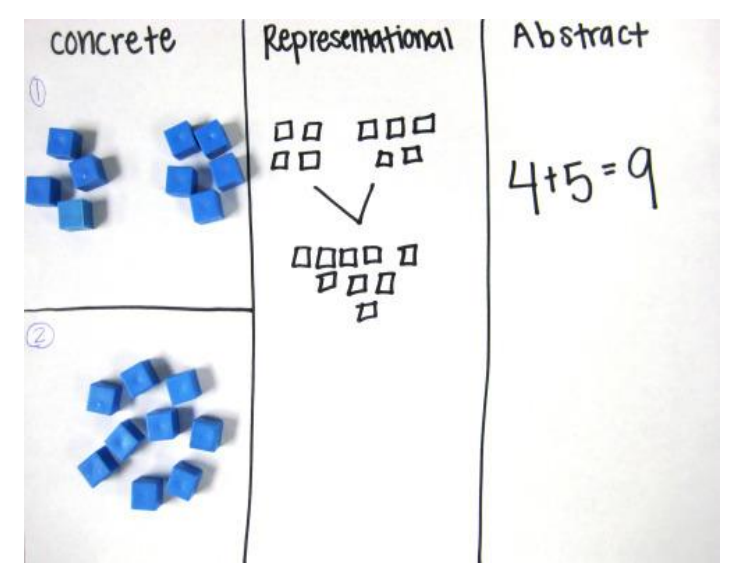

Figure 1. CRA Model

The research in mathematics has shown that teaching abstracts algorithms without teaching for conceptual understanding to young children is harmful [22]. Algorithms that require children to focus on rules, such as "carry the one", prevent them from thinking and developing number sense. It is important that young students use concrete objects to make sense of the processes involved in mathematics concepts such as addition of whole numbers.

Miller and Hudson [23] provided several guidelines for helping students with disabilities understand math concepts: use several models to represent the concepts, use appropriate lesson structures for specific concepts, use appropriate mathematical language, use real life applications, and use clear and explicit instruction.

The lessons should include giving an advanced organizer, describing and modeling, conducting guided practice, conducting independent practice, conducting problem-solving practice, administering facts review, and providing feedback [3]. These procedures have been shown to be effective with teaching basic facts to students with learning difficulties.
Research has shown that using a method called, "Touch Math" has been effective in helping children with special needs master addition facts [24, 25]. Touch Math uses counting points on numbers in order to help the students understand basic math concepts, such as addition of whole numbers. With Touch Math, numbers 1 through 5 have single "Touch Points" or dots on the digits that correspond with the value of the digit. For example, the digit 4 has four dots that help the student add with the number four. The student touches and counts each dot one time. Numbers 6 through 9 have double "Touch Points" or a dot with a circle around it. The double "Touch Points" are touched twice by the student [24].

\section{Methodology}

A single subject case study was conducted to help the student learn addition concepts. Information from a pre-test was used to (a) identify the unique needs of the student, (b) provide guidance in the selection of instructional content and materials, and (c) provide information for the creation of an individualized education plan (IEP). In the study, the student's progress was monitored to evaluate progress of the learning [26]. The study utilized what was believed to be an adequate representation of content, appropriate scope and sequence of the content and developmentally appropriate content to insure accurate measures.

The student completed the third grade during the 2014-2015 school year. The student attends school in an area where there is an approximate twelve week summer break. The lessons were conducted during this summer 2015 break; therefore the student was not receiving any other math instruction during the research period. The researchers worked with the same student during the summer break of 2014 on place value concepts; therefore the student was very comfortable working with the researchers. The student appeared to feel free to interact both positively and negatively during the work sessions.

The researchers developed a pretest, formative lessons, and a posttest modeled after the work of Mercer and Miller [3]. The student was given a pretest to assess knowledge of whole number single digit and double digit addition. The assessment included addition of single digit by single digit with and without renaming; two digit by single digit without renaming; two digit by single digit with renaming 1's, and both; double digit without renaming; and double digit with renaming 1's, 10's, and both [27].

Based on the results of the pretest, an individualized education plan (IEP) was designed for the student. A minimum of ten lessons were provided for the student as recommended by Mercer and Miller [3] and additional lessons were used when it 
was determined necessary by the researchers. Two review lessons on two digit place value preceded the addition lessons. The initial plan was to use concrete models or manipulatives in lessons one through three, semi-concrete models or drawings in lessons four through six, lesson seven was used to teach abstract strategies, and abstract models in lessons eight through ten [3]. The instructional timeline in this study was individualized and adjusted according to the student's needs.

\section{Results}

The student's comprehension of single and double digit addition of whole numbers with and without regrouping was assessed. The student was given a pretest to assess knowledge of one and two digit addition with and without regrouping. Based on the results of the pretest, an individualized education plan (IEP) was designed for the student. A posttest was used to evaluate the student's overall progress after the lessons over addition.

\subsection{Pretest}

The pretest consisted of ten addition problems Problems one and two had one digit addends. Problems three and four addressed had one and two digit addends with no regrouping. Problems five and six had two digit addends with no regrouping. Problems seven and eight had one and two digit addends with regrouping. Problems nine and ten had two digit addends with regrouping. See Figure 2 below.

The student only attempted the first two problems. The student was given the base ten blocks to use if needed. The student counted unit blocks to represent the number in the first and second addend. The student circled the first addend in each problem, used one hand to cover the blocks representing the first addend, then "counted on" the blocks representing the second addend. The student had been taught to circle the largest addend then "add on" the other addend to calculate the sum. In each case the student circled the first addend or the addend on top. Perhaps the student thought it was larger because it was higher on the page or perhaps the student thought that the procedure was to circle the first addend and then add the second addend. In both problems that the student worked, the second addend was actually the larger addend. The student recorded the correct answer for problem one and problem two, both of which had single digit addends.

The student did not want to work any of the remaining problems with a two digit addend. The student stated that the problems were "too hard" and refused to attempt any of the other problems; thus working $20 \%$ of the problems on the pretest correct. See Figure 2 below.

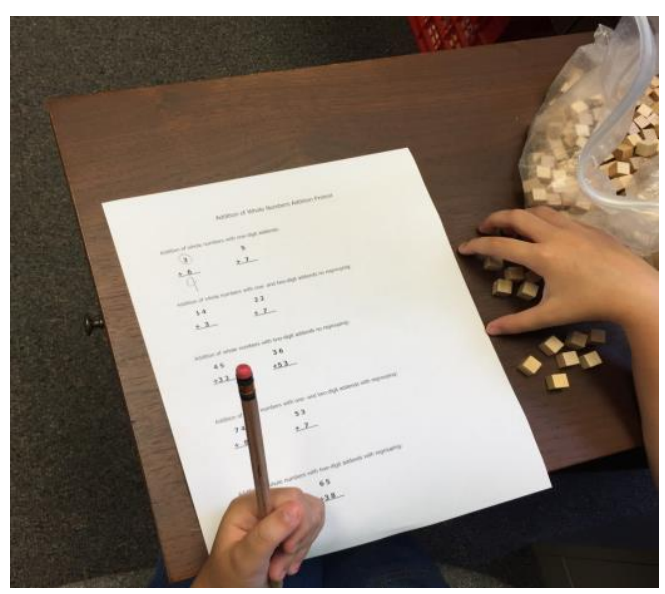

Figure 2. Addition Pretest

\subsection{Individualized Education Plan}

The individualized education plan was adjusted to meet the student's needs. Two review lessons on place value took place with the student as planned. It was determined that the student had sufficient recollection of place value concepts to begin the addition lessons. Five lessons were used using the base ten blocks as concrete models, seven lessons were used utilizing drawings of the base ten blocks for the semi-concrete models, and three lessons were used using abstract models for the addition problems.

Five lessons were given using concrete models instead of the proposed three lessons. Each lesson lasted approximately twenty minutes and the base ten blocks were utilized as planned.

The first problem in lesson one was " $5+9$ ". The student was asked, "Which number is bigger?" The student responded, "Five is bigger". The researcher rephrased the question, "Were you bigger when you were five years old or were you bigger when you were nine years old?" The student responded, "Nine". The strategy of using the student's age to determine which addend was larger worked with the first problem and with subsequent problems throughout the lessons.

The student was shown how to rename the solution when there were more than ten units in the ones place. For example when working " $15+8$ ", the initial solution was one ten and thirteen ones. The student was shown how to rename the thirteen ones to one ten and three ones. The final answer was displayed as two tens and three ones. The student was making an error when adding a two digit number with a one digit number with regrouping. For example the student was given the problem " $18+8$ ". The student added the numbers in the ones place and got the correct answer, sixteen ones. However, when the student was renaming the sixteen units to one ten and six units, the student reached for the ten that was part of the first addend, eighteen. This error was 
observed in the second and third lesson also. For this reason, it was determined that the student needed more than the proposed three lessons to master the concrete stage of addition with one and two digit addends.

In Figure 3 below, the student was adding " $64+$ 8 ". The student showed the first addend, sixty-four, as six ten sticks and four ones. The student showed the second addend, eight, with eight ones. The student added the ones together by covering the eight ones, since eight is larger than four, and then adding on the four ones, "nine, ten, eleven, twelve". The student was able to rename the twelve ones to one ten and two ones by getting a ten stick and aligning ten ones next to it. The student then removed the ten ones and replaced them with the one ten stick. The student was able to add six tens plus one ten. The student was asked for the sum and answered correctly after counting the blocks. The student counted the blocks correctly, "Ten, twenty, thirty, forty, fifty, sixty, seventy," then counted on the ones, "seventy-one, seventy-two". The student was able to find the number card, "72", and place it next to the seven tens and two ones.

When needed in the sum, the student was able to rename eleven to one ten and one unit, twelve ones to one ten and two ones, thirteen to one ten and three ones, etc. However, each time that the student needed to rename more than ten ones in the sum, the student had to align ten ones next to the ten stick, then remove the ten ones and replaced them with the one ten stick. The student could not anticipate that fourteen was one ten and four ones, fifteen was one ten and five ones, etc. The student did not understand that if twelve ones were in the solution, two ones would remain and the rest would be replaced with one ten.

For each problem the student was asked to verbalize the solution. After having counted the ones, regrouped if necessary, then counted the tens, the student still had to count the blocks in the solution. The student did not recall the sum of the blocks that had been counted.

After five lessons with concrete models using the base ten blocks, the student understood how to represent the problem using base ten blocks, determine which addend was larger, count on the other addend, state the sum of the ones, rename the blocks in the solution set when needed, count the blocks in the solution, state the sum of the tens, state the solution, and record the solution using number cards. After five lessons using the base ten blocks it was determined that the student was prepared to proceed to the semi-concrete stage or the representational stage.

In the first lesson of the Semi-Concrete stage or Representational stage the student was shown how to draw pictures of the base ten blocks to represent addition problems. The student worked addition problems with one and two digit addends with and without regrouping throughout the seven lessons. The first problem illustrated in Figure 4 is " $46+17$ " and the second problem is " $82+5$ ".

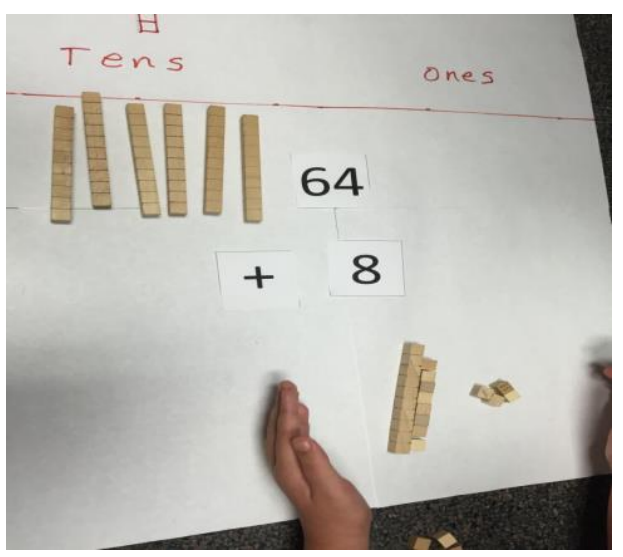

Figure 3. Concrete Stage

In the first problem of Figure 4, the student first illustrates the problem using a stick mark for each tens stick and a small mark for the ones. Forty-six is illustrated with four ten sticks and six small marks for the ones. Seventeen is illustrated with one ten stick and seven small marks for the ones. When adding the ones, the student points to the seven since it is larger, then adds on six ones saying and pointing to each mark, "eight, nine, ten, eleven, twelve, thirteen". The student records the number "thirteen" in the ones place. The student then adds the tens by pointing to the four tens, since it is larger, then adds on one ten saying, "five". The student records "five" under the tens column. To rename the thirteen ones, the student draws a "circle" around ten ones. The student draws a line over to the tens column and writes a " 1 " to show that the ten ones make one ten stick. The student is then told that the 5 tens and thirteen ones can be written in a different way, since ten ones make one ten and have been moved to the tens place. The student is asked how many ones are left after the ten ones have been moved. The student counts the ones, correctly responds, "three", and records the number "three" in the ones place. The student is asked how many tens there are, now that there is an extra ten. The student recounts all the tens, answers correctly, "six", and records the number "six" in the tens place. The student is not able to recall the sum or realize that the previous sum of five tens is recorded in the tens place and all that needs to be done is add one more ten to the five tens. The student is asked to verbalize the solution and correctly responds, "sixty-three".

In the second problem shown in Figure 4, the student drew the representations for " $82+5$ ". The student correctly drew eight ten sticks and two small marks to illustrate eighty two. Five ones was illustrated with five small marks. Next the student 
added the ones or " $2+5$ ". The student begins with five since it is larger, points to the marks and counts on, "six, seven", and correctly records "seven" under the ones column. Next the student adds the tens and correctly records, "eight" under the tens column. There is no regrouping needed in the second problem of Figure 4. The student is asked to verbalize the answer and correctly responds, "eighty-seven".

When grouping ten ones together, the student begins counting the unit marks of the second addend and continues adding the unit marks of the first addend in order to count ten unit marks in the "circle". After drawing the regrouping, the student is asked to rename the initial solution. Each time the student uses the pictures to recount the ones and recount the ten blocks before recording the simplified solution. The student was not able to simplify the solution without recounting the blocks in the illustration.

The initial plan was to use three lessons with the semi-concrete models or drawings of the base ten blocks. Each lesson consisted of four problems. The student made errors throughout the first five lessons therefore seven lessons were used rather than the proposed three. One error was recording the incorrect number of tens in the initial solution but then recording the correct answer after the regrouping. This was because the blocks were recounted each time regrouping was involved. In a second problem the student carelessly recorded the second addend as the solution. A third error was caused when the student recorded the number of ones in the tens column and the number of tens in the ones column. A fourth error in the solution was caused because the drawing did not illustrate the correct number of ones for the second addend. On a fifth problem the student forgot to add the tens and recorded the number of tens in the first addend in the solution. Because of these errors, seven lessons were used instead of the proposed three. The semiconcrete stage seemed to be quite complex for this special needs child.

The student did not make any significant errors in the last two lessons. The student was able to draw the semi-concrete representations for the two addends in the problem, add the ones and tens by counting the blocks in the picture, record the number of ones and tens in the appropriate column, group ten ones together if needed and draw an arrow showing that ten ones add one ten to the tens column, recount the blocks, record the simplified solution, and verbalize the answer correctly. After success on lessons six and seven, the student proceeded to the abstract stage.

The student was very familiar with the abstract stage as this was the vertical form that was used in the public school that the student attends.

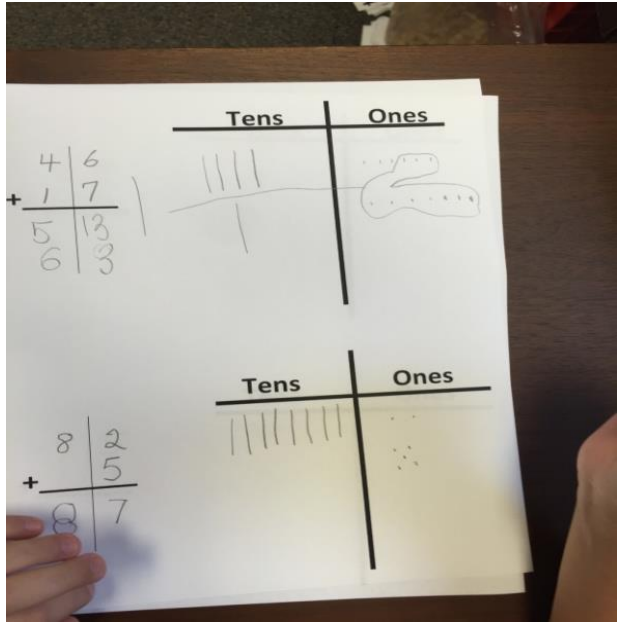

Figure 4. Semi-Concrete Stage

The student had been taught to use "Touch Points"; so used that method when adding the whole numbers. The student was given one page with six problems written in vertical form (see Figure 5 below). The student was able to determine which digit in the ones place was larger, add the two digits by counting on from the larger addend, record the sum in the ones column with and without regrouping, and repeat the process for the tens place. The student was successful in working problems in this stage. The three lessons that were initially planned were used. The only error the student made was recording a two digit sum in the ones place similar to what was the procedure in the semi-concrete stage. Each time, the student erased the "ten" that was recorded in the "ones" place and wrote it on top of the "tens" place. The student made no errors on the third lesson, so was allowed to proceed to the posttest.

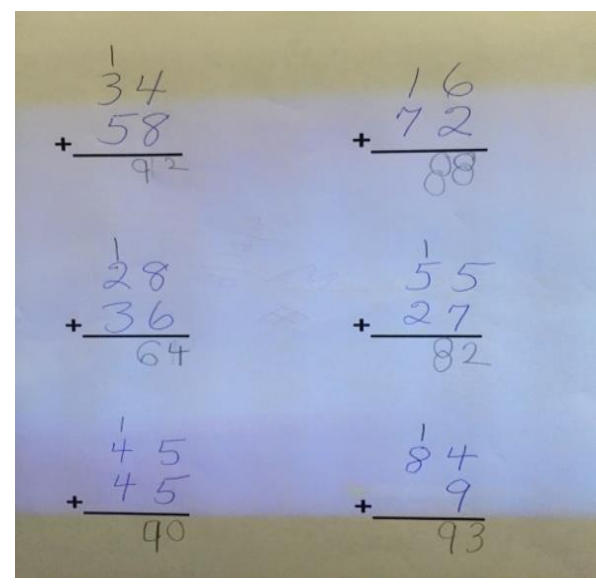

Figure 5. Abstract Stage

\subsection{Posttest}

The student was given the posttest after completing the Individualized Education Plan (IEP). 
The student had been given two review lessons on place value, five lessons on the concrete stage, seven lessons on the semi-concrete stage, one lesson of instruction, and three lessons in the abstract stage. The student was given ten problems similar to the ones on the pretest which covered one and two digit addition with and without regrouping. The student was able to work each problem on the Posttest correct or $100 \%$. This was quite an improvement from the $20 \%$ worked correctly on the Pretest.

\section{Conclusions}

The student was successful at the concrete stage after five lessons instead of the three lessons that were initially planned. As previously noted, the student was not able to rename a number such as 12 ones to 1 ten plus 2 ones without aligning ten ones next to a ten stick, remove the ten ones and replace them with one ten stick. Also the student was not able to verbalize the sum without recounting the blocks. The student was able to solve the problems with $80 \%$ accuracy after five lessons, and then proceeded to the semi-concrete or representational stage.

In the semi-concrete stage, the student was successful after seven lessons instead of the proposed three lessons. The lessons in this stage were quite difficult for this special needs child. The student probably had more difficulty with this stage because of having to go back and forth from the problem to the picture. Also, there are so many steps involved in solving a problem with the pictures. As in the previous stage, the student had to recount 10 marks before grouping the ten ones together. For example, after having counted twelve ones, the student did not know that two blocks would be left out of the group and the rest of the ones would be the ten ones in the group. The student had to recount the ones and tens blocks in order to rename the solution. The student solved the problems with $80 \%$ accuracy after the seventh lesson. Then the student was able to proceed to the abstract stage.

The student was successful in the abstract stage. This is possible due to the fact the student had solved problems in this manner in the classroom. The student was fluent in using "Touch Points" and was able to get $80 \%$ of the problems correct on each lesson. This led to the $100 \%$ achieved on the posttest.

It was not known whether the student made the connections between the concrete, semi-concrete and abstract stages. More work is needed with the student to make this determination. The student should be given the opportunity to solve the same problem concretely, semi-concretely, and abstractly. Questions should be asked to see if the student can make connections between the three methods.

The results of the study will be provided to the student's classroom teacher with the hope that the student's needs will be more adequately addressed during the next school year.

\section{References}

[1] National Council of Teachers of Mathematics, Principles and Standards for School Mathematics, NCTM, Reston, VA, 2000, p. 78.

[2] Common Core State Standards Initiative, Preparing America's Students for College \& Career, Mathematics Standards, 2014, Grade 2, p. 18.

[3] Mercer, C.D. and S.P. Miller, "Teaching students with learning problems in math to acquire, understand, and apply basic math facts", Remedial and Special Education, Vol. 13, 1992, pp. 19-35.

[4] Hanich, L.B. and N.C. Jordan, "Achievement-related beliefs of third-grade children with mathematics and reading difficulties", The Journal of Educational Research, Vol. 97 No.5, 2004, pp. 227-233.

[5] Wynn, K., "Children's understanding of counting", Cognition, Vol. 36, 1990, pp.155-193.

[6] Jordan, N.C. and L.B. Hanich, "Mathematical thinking in second-grade children with different forms of LD", Journal of Learning Disabilities, Vol.33 No. 6, 2000, pp.567-578.

[7] Gleman, R. and C.R. Gallistel, The child's understanding of number, Harvard University Press, Cambridge MA, 1978.

[8] Gelman, R and E. Meck, "Preschoolers' counting: Principles before skill”, Cognition, Vol.13, 1983, pp. 343359.

[9] Hanich, L. B., N.C. Jordan, D. Kaplan, and J. Dick, "Performance across different areas of mathematical cognition in children with learning difficulties", The Journal of Educational Psychology, Vol. 93, 2001, pp. 615-625.

[10] Fuchs, L.S., P.M. Seethaler, S.R. Powell, D. Fuchs, C.L. Hamlett, "Effects of preventative tutoring on the mathematical problems solving of third-grade students with math and reading difficulties", Council for Exceptional Children, Vol.74 No. 2, 2008, pp. 155-173.

[11] Dweck, C. S. "Motivational processes affecting learning", American Psychologist, 41, 1986, pp. 10401048.

[12] Dweck, C. S. and E.L Leggett, "A social-cognitive approach to motivation and personality", Psychological Review, Vol. 95, 1988, pp. 256-273

[13] Ostad, S. A., "Developmental differences in addition strategies: A comparison of mathematically disabled and mathematically normal children", British Journal of educational Psychology, Vol. 67, 1977, pp. 345-357. 
[14] Hart, L. R., "Affective variables in mathematics education", Elementary School Journal, Vol. 84, 1984, pp.558-581.

[15]Hughes, M. Children and number. Basil Blackwell, Oxford, England, 1986.

[16] Huttenlocher, J., N.C. Jordan, and S.C. Levine, “A mental model for early arithmetic", Journal of Experimental Psychology: General, Vol. 123, 1994, pp.284-296.

[17] Jordan, N. C., J. Huttenlocher, and S.C. Levine, "Differential calculation abilities in young children from middle and low income families", Developmental Psychology, Vol. 28, 1992, pp. 644-653.

[18] Jordan, N. C., J. Huttenlocher, and S.C. Levine, "Assessing early arithmetic abilities: Effects of verbal and nonverbal response types on calculation performance of middle and low income children". Learning and Individual Differences, Vol. 6, 1992, pp. 412-432.

[19] Miller, S.P. and B.J. Kaffar, "Developing addition with regrouping competence among second grade students with mathematics difficulties", Investigations in Mathematics Learning, Vol. 4 No. 1, 2011, pp. 24-49.

[20] Flores, M.M. "Teaching subtraction with regrouping to students experiencing difficulty in mathematics", Preventing School Failure, Vol. 53 No. 3, 2009, pp. 145152.

[21] Miller, S.P. and C.D. Mercer, "Using data to learn about concrete-semiconcrete-abstract instruction for students with math disabilities", Journal of Learning Disabilities Research and Practice, Vol. 8, 1993, 89-96.

[22] Kamii, C. and A. Dominick, "The harmful effects of algorithms in grades 1-4", National Council of Teachers of Mathematics Yearbook, 1998, pp. 130-140.

[23] Miller, S.P. and P.J. Hudson, "Helping Students with Disabilities Understand What Mathematics Means", Teaching Exceptional Children, Vol. 39 No. 1, 2006, pp. 28-35.

[24] Wisniewski, Z.G. and D. Smith, "How Effective is Touch Math for Improving Students with Special Needs Academic Achievement on Math Addition Mad Minute Timed Tests?", ED 469 445, U.S. Department of Education, ERIC, 2002. pp. 1-13.

[25] Green, N.D., "The Effectiveness of the Touch Math Program with Fourth and Fifth Grade Special Education Students", Western Governors University, Touch Math, 2009, pp. 1-67.

[26] Parmar, R.S., R. Frazita, and J.F. Cawley, "Mathematics Assessment for Students with Mild Disabilities: An Exploration of Content Validity", Learning Disability Quarterly, Vol. 19, 1996, pp. 127-136.

[27] Cawley, J.F., and R.S. Parmar, "Mathematics assessment for students with mild disabilities: frameworks and practices", Learning Disabilities: A Contemporary Journal, Vol. 1 No. 1, 2003, pp. 20-26. 